\title{
КЕЙС-ТЕХНОЛОГИИ В ФОРМИРОВАНИИ УНИВЕРСАЛЬНЫХ КОМПЕТЕНЦИЙ СТУДЕНТОВ НЕЯЗЫКОВЫХ СПЕЦИАЛЬНОСТЕЙ ПРИ ОБУЧЕНИИ ИНОСТРАННОМУ ЯЗЫКУ 1
}

\section{CASE TECHNOLOGIES IN THE FORMATION OF UNIVERSAL COMPETENCES OF STUDENTS OF NON-LANGUAGE SPECIALTIES IN TEACHING A FOREIGN LANGUAGE ${ }^{2}$}

\section{N. Nazarova}

S. Nazarov

Summary: In the current situation, the training of specialists at the university is aimed not only at the formation of professional, but also universal competencies that provide the ability to think systematically, critically assess problem situations, and look for various resources to solve professional problems. A unique means of forming universal competencies of students of non-linguistic specialties in the study of the discipline "Foreign language» are case technologies, the structure, classification and functions of which are investigated in this article.

Keywords: universal competencies, case technologies, students of nonlinguistic specialties, higher education system.

\author{
Назарова Наталья Александровна \\ К.п.н., дочент, Омский государственный \\ педагогический университет \\ geybel@rambler.ru \\ Назаров Сергей Владимирович \\ К.п.н., дочент, Омский государственный \\ педагогический университет \\ svnazaroff@rambler.ru
}

Аннотация: В современной ситуации подготовка специалистов в вузе направлена не только на формирование профессиональных, но и универсальных компетенций, обеспечивающих способность мыслить системно, критически оценивать проблемные ситуации, искать разнообразные ресурсы для решения профессиональных задач. Уникальным средством формирования универсальных компетенций студентов неязыковых специальностей при изучении дисциплины «Иностранный язык» являются кейс-технологии, структура, классификация и функции которых исследуются в данной статье.

Ключевые слова: универсальные компетенции, кейс-технологии, студенты неязыковых специальностей, система высшего образования.

школы должен быть способен самостоятельно принимать решения, оценивать и решать задачи в повседневной жизни; должен уметь адаптироваться к новым нестандартным ситуациям; должен понимать необходимость продолжать обучение после окончания школы в профессиональных учебных заведениях и быть замотивированным на саморазвитие и самообучение.

В системе высшего образования также произошел переход на ФГОС 3++, что привело к появлению универсальных компетенций в образовательных программах [10]. В нормативно-правовых документах универсальные компетенции трактуются как комплексные характеристики готовности выпускника применять полученные знания, умения и личностные качества в стандартных и изменяющихся ситуациях профессиональной деятельности, то есть это так называемые надпрофессиональные навыки или «мягкие умения» (soft skills). Согласно стандартам высшего образования (ФГОС 3++) принято выделять следующие категории универсальных компетенций: системзнания выпускника школы очень часто устаревают к мо-
менту его выхода на рынок труда, поэтому в школьном
образовании сейчас идет смещение акцента от предмет-
ных знаний или знаний фактов к так называемой «новой
грамотности», когда знание изучаемых дисциплин поме-
щается в ситуации его применения для решения учени-
ком реальных жизненных задач. В результате выпускник

Исследование выполнено в рамках гранта фонда развития науки ОмГПУ

The study was carried out within the framework of a grant from the Omsk State Pedagogical University Science Development

Fund 
ное и критическое мышление; разработка и реализация проектов; командная работа и лидерство; коммуникация; межкультурное взаимодействие; самоорганизация и саморазвитие; безопасность жизнедеятельности [1].

Таким образом, цель образования в современном обществе состоит не только в том, чтобы давать знания, но и в том, чтобы научить учащихся и студентов пользоваться теми средствами, которые помогут им обладать знаниями, необходимыми при решении различных проблемных ситуаций в личной, общественной и профессиональной деятельности. Изменение целей образования повлекло за собой обновление всех компонентов образовательного процесса и, прежде всего, методов обучения и оценки образовательных результатов [11]. Именно этим и объясняется повышенное внимание и большой интерес к кейсам на разных ступенях системы образования.

Особенно популярны кейс-технологии на вузовской ступени образования. Исследователями уже доказано, что формирование и развитие разного рода компетенций средствами кейс-заданий значительно повышает эффективность профессионального обучения студентов благодаря их практической направленности и интерактивному формату. Кроме того, реализация кейс-технологий в процессе обучения, позволяет развивать аналитические, практические, творческие, коммуникативные навыки, умения самоанализа и рефлексии, личные качества, системы ценностей и т.д. [4]

Кейс-технологии также являются одним из наиболее эффективных инновационных средств оценивания компетенций, поскольку с их помощью становится возможным отслеживание динамики профессионального развития будущих специалистов, а также осуществление комплексного подхода к оценке всех составляющих этих компетенции [2].

Анализ литературы позволил нам выявить разные виды классификаций кейсов, в зависимости от оснований и подходов $[4,5,7]$. Самая популярная классификация кейсов - это их деление по содержанию. Выделяют

- структурированные кейсы (highly structured cases) - короткое и точное изложение ситуации с конкретными цифрами и данными;

- неструктурированные кейсы (unstructured cases) - материал с большим количеством данных, предназначенный для оценки стиля и скорости мышления, умения отделить главное от второстепенного и навыков работы в определённой области. Это самые сложные кейсы;

- первооткрывательские кейсы (ground breaking cases) - раскрывающие способность студентов к нестандартному мышлению и выдвижению креативных идей;
- «маленькие наброски» (short vignetts), знакомящие только с ключевыми понятиями, где при анализе проблемы студентам необходимо использовать собственные знания.

Другим подходом в классификации является разделение кейсов по степени сложности. Здесь различаются:

- иллюстративные учебные ситуации-кейсы, где на конкретном примере происходит обучение алгоритму принятия решения в определенной ситуации. Это кейсы низкой сложности («ситуации-иллюстрации»);

- учебные ситуации-кейсы с формированием проблемы (прикладные упражнения), в которых описывается ситуация в конкретный период времени, выявляются и четко формулируются проблемы. Это кейсы средней сложности («ситуации-оценки»);

- учебные ситуации-кейсы без формирования проблемы, в которых описывается более сложная, чем в предыдущем варианте ситуация, где проблема четко не выявлена, а представлена в статистических данных, оценках экспертов и т.д. Это кейсы высокой сложности («ситуации-проблемы»).

Некоторые исследователи считают, что в классификацию кейсов может входить шкала «мертвые и живые кейсы». К «мертвым» они предлагают отнести кейсы, в которых содержится вся необходимая для анализа информация. В «живом» кейсе предполагается изначально предложить минимум информации, чтобы в процессе решения возникла необходимость найти новые дополнительные сведения. Различаются также кейсы сюжетные (с включением рассказа о произошедших событиях, действиях отдельных лиц и организаций) и бессюжетные, которые представляют собой статистические материалы, расчеты.

В зависимости от субъекта кейсы подразделяются на три категории: личностные, где действую конкретные личности, менеджеры, политики, руководители; организационно-институциональные, где действуют организации, предприятия, их подразделения; многосубъектные, где действуют несколько субъектов.

Для классификации имеет значение и то, что представляет собой методическая сторона кейса. Выделяют вопросные кейсы, состоящие из ряда вопросов, на которые необходимо дать ответ при решении; кейсы-задания или проблемные кейсы, которые предполагают формулировку задачи и ее решение, а результатом является определение основной проблемы и всегда - оценка сложности решения; проектные кейсы, в которых результатом является программа действий по преодолению проблем, появившихся в ситуации. 
Кейсы также могут быть

- обучающими, когда в типичных ситуациях отрабатывается автоматизм навыков и способы поиска решений. В данном кейсе на первом месте стоят воспитательные и учебные задачи, что предопределяет важную часть условности при отражении в нем жизни;

- практические кейсы, отражающие максимально приближенно реальную ситуацию или случай;

- научно-исследовательские кейсы, направленные на проведение исследовательской деятельности. Их главная задача состоит в приобретении нового знания о ситуации и поведения в ней. Отличительной особенностью этих кейсов является: обзор реальной проблемной ситуации, выбор для решения проблемной ситуации, общая цель и групповая работа по принятию решения, отсутствие авторского восприятия проблемы;

- оценочные кейсы - кейс-задания, направленные на проверку сформированности профессиональных компетенций будущих специалистов в соответствии с образовательным стандартом.

По источнику информации кейсы подразделяют на «полевые», основанные на реальном фактическом материале (из производственного опыта), имеющие выход на профессиональную деятельность; и «кресельные» - вымышленные кейсы (смоделированные, гипотетические, предполагаемые ситуации).

Все это многообразие кейсов, направленных на решение поставленных образовательных задач разнообразными способами, объясняет, почему данные технологии занимают ведущие позиции в современной системе образования.

В современном профессионально-ориентированном обучении студентов неязыковых факультетов кейстехнологии активно применяются в преподавании иностранного языка. Это обусловлено несколькими причинами. Во-первых, использование кейс-технологий направлено на дальнейшее развитие коммуникативной компетенции (иноязычной, социокультурной), что и является основной целью преподавания дисциплины «Иностранный язык» для студентов неязыковых специальностей, а во-вторых, решение «кейс-заданий» способствует развитию других категорий универсальных компетенций, обеспечивая диалогичность, самоактуализацию, творчество, субъект-субъектного взаимодействие и т.д. [8].

В зависимости от поставленных целей и задач конструируется определенный вид кейса [6]. В самом общем виде кейс-задание состоит из:

- Вводной части, это описание самой ситуации;

- Основной части, содержащей вопросные или проблемные задания;

- Завершающая часть представляет дополнительную информацию, которая позволит лучше разобраться в «кейсе»: вопросы, библиография, фотографии персонажей, схемы, таблицы.

Решение кейса начинается с ознакомления с проблемной ситуацией, которая обычно представляет собой профессионально-ориентированный текст с включенной в него проблемой по специальности. В результате студенты уже на первом этапе не просто читают и переводят текст (ситуацию), но анализируют и интерпретируют полученную информацию, а также рассматривают возможные варианты решения заявленной проблемы, определяя круг задач для ее решения, планируя их реализацию и оценивая ожидаемые результаты. Перечисленные выше умения являются характеристиками УК-1 и УК-2, они продолжают развиваться на других этапах работы с кейсом: и при его решении (поиск информации, анализ, обобщение, суждение, аргументация и т.д.) и при предоставлении результатов (предложение решений, презентация, управление проектом и его защита, публичное выступление и т.д.).

Кроме исследовательских, аналитических, менеджерских и других навыков, входящих в структуру УК-1 и УК-2, использование кейсов в учебном процессе способствует развитию навыков социального взаимодействия. Студенты, решая кейсы, учатся работать в команде, строить общение, обмениваться опытом, соблюдать нормы, формируя таким образом свою коммуникативную грамотность (УК-3). Решение кейс-заданий на иностранном языке также способствует развитию межкультурной профессиональной компетенции будущих специалистов (УК-5), в силу межпредметного характера кейсов, а также междисциплинарности самого предмета «Иностранный язык». Студенты, решая профессионально-ориентированные задачи в кейсах, учатся выстраивать социальное профессиональное взаимодействие со всеми участниками группы и другими задействованными лицами, учитывая их различные формы сознания, особенности деловой и общей культуры, преодолевать коммуникативные барьеры и решать конфликтные ситуации различных поликультурных и социальных групп.

Характеристики УК-6 проявляются в умениях обучающихся оценивать свои ресурсы и оптимально их использовать для успешного выполнения поставленной задачи. Самоорганизацию и самоконтроль можно проследить с помощью листов самооценки и рефлексии на заключительном этапе выполнения кейс-задания.

Таким образом, мы видим, что методика преподавания иностранного языка направлена на развитие всех универсальных компетенций студентов неязыковых специальностей и становление их личностной культуры, 
а реализация кейс-технологий на уроках данной дисциплины усиливает этот эффект, способствуя достижению интегративных результатов студентов не только на уровне личности, но и охватывая ее общекультурные и профессиональные характеристики.

Примером может послужить кейс-задание, предлагаемое студентам неязыковых специальностей кафедрой иностранных языков Омского государственного педагогического университета при изучении третьего модуля «Социально-культурная сфера общения» (дисциплины «Иностранный язык», бакалавриат):

Кейс-задание. Ситуация. AKA telecommunications in India

AKA is a Swedish software technology and design company. They create products and services for the computer and telecommunications industries. Six months ago they started work on a major project with an Indian software developer based in Bangalore. A number of project managers from Sweden, some of them women, relocated to India to manage the different parts of the project. They are working with local managers, and software designers and engineers.

Since the Swedish managers arrived, things have not gone as well as AKA hoped. The standard of work is very high, but the project is behind schedule, and several important delivery dates have been missed. Also, the relationship between the Swedish managers and their Indian teams is getting worse. Meeting to review progress and make decisions are often very long, and the outcome is not always clear. There have also been some communication problems, even though everyone speaks "good" English.

The Swedes now see their Indian colleagues as disorganized, inefficient and unwilling to take responsibility. The Indians think Swedes are too informal and relaxed at work, don't say what they want, and are unable to make decisions.

\section{$\underline{\text { Task1 }}$}

Make a list of the main problems. What are possible reasons for these problems?

\section{Task 2}

How could management improve the situation?

\section{Task 3}

If you were relocated to a different country to work on a joint venture, how would you prepare yourself? Make a plan.

\section{Task 4}

Imagine someone from a different cultural background comes to your University. How would you explain your work culture? Think about: dress code, attitudes towards time and deadlines, the working day, etiquette, politeness, etc.

\section{Task 5}

Work out some suggestions and recommendations as to how to improve the situation. Discuss the pros and cons of each suggestion, then choose one to recommend to the management of the joint venture. Present your choice giving reasons.

\section{The Expert View}

National culture is patterns of behavior and attitudes that are learned and shared among a group. Problems between people from different cultures can occur because of their different responses to particular situations. For example, some cultures value personal relationships more than the rule of the law; others believe regulations must be obeyed, independent of friends or family. To deal with intercultural problems you need to understand your own culture, be sensitive to other people's behaviour and attitudes, and be interested in other people's viewpoints.

Это учебная ситуация-кейс на английском языке без формирования проблемы; она сюжетная, то есть содержит названия организаций и описание происходящих событий; а также «живая», так как предполагает необходимость в дополнительных сведениях (об особенностях национальной культуры в Швеции и Индии). Кейсзадание направлено на самостоятельное выявление проблемы (Task 1, Task 4), анализ наличных ресурсов и принятие решений по устранению данной проблемы с указанием альтернативных путей ее решения (Task2, Task 3, Task 5). Все это развивает, прежде всего, «мягкие навыки» (soft skills), а именно: навыки социального взаимодействия - построение коммуникации на иностранном языке, умения договариваться, работать в группе, разрешать и управлять конфликтами, адаптироваться к культуре общения, следовать нормам профессиональной этики (УК-3, УК-4, УК-5); навыки и умения мыслительной деятельности высшего порядка: исследовательские, аналитические, творческие и т.д.; менеджерские и ориентационные навыки: принятие решений, адаптивность к изменениям и т.д. (УК-1, УК-2).

Оценка умений, входящих в УК-6 и УК-7 (самоорганизация, самоконтроль и самообразование), осуществляется при решении указанного кейса на этапе рефлексии, когда студентам выдаются листы самооценки, где они сами оценивают не только полученный результат, но и свои способности управлять своим временем, способности самостоятельно выстраивать траектории собственной деятельности и возможности их совершенствования.

Таким образом, кейс-технологии, обладая огром- 
ным потенциалом, способствуют формированию всех универсальных компетенций бакалавров при изучении дисциплины «Иностранный язык». Кроме того, с помощью кейс-тестинга можно получить объективную и комплексную оценку уровня сформированности всех универсальных компетенций [3]. Кейс-тестинг объединяет несколько кейс-заданий, интегрирующих знаниево-ориентированные оценочные средства и проблемные ситуации. Каждый кейс-тест проверяет определенную «порцию функциональности» в рамках определенной компетенции» [9]. При решении кейс-тестов студент должен использовать понятия и методы из разных дисциплин, переносить технологии из освоенной области в новую сферу, строить моде- ли, делать выводы, оценивать их адекватность (т.е. использовать освоенные «мягкие навыки») [7]. Кейстестинг дает возможность в целом оценить успешность будущего специалиста при решении определенных профессионально-ориентированных задач.

Таким образом, рассмотрев и проанализировав потенциал кейс-технологий в процессе обучения иностранному языку, можно сделать вывод об их востребованности и необходимости в формировании универсальных компетенций студентов неязыковых специальностей. Кейс-технологии являются уникальным средством получения требуемых результатов на всех уровнях образования и самообразования.

\section{ЛИТЕРАТУРА}

1. Белкина В.В., Макеева Т.В. Концепт универсальных компетенций высшего образования // Ярославский педагогический вестник. - 2018. - № 5. - С. 117-126.

2. Дроботенко Ю.Б. Оценка языковых компетенций студентов неязыковых специальностей // Материалы международной научно-практической конференции «Актуальные проблемы лингвистики и методики преподавания иностранных языков», ОмЮА, Омск 29 марта, 2019. - С. 15-19.

3. Казакова, Е.И., Тарханова, И.Ю. Оценка универсальных компетенций студентов при освоении образовательных программ // Ярославский педагогический вестник. 2018. № 5. С. 127-135.

4. Новиков А.Е., Прутченков А.С. Кейс-стади [Электронный ресурс]. URL: http://www.myshared.ru/slide/326674/

5. Пахтусова Е.Э. Метод кейсов в обучении иностранному языку в вузе / Е.Э. Пахтусова. — Текст : непосредственный // Молодой ученый. — 2014. (66). — C. 532-534. — URL: https://moluch.ru/archive/66/11034/

6. Перевощикова Е.Н., Лекомцева А.А. Конструирование кейс-задания как оценочного средства // Современные проблемы науки и образования. - 2016. - № 3.; URL: http://www.science-education.ru/ru/article/view?id=24851

7. Шварева, О.В. Кейс-тест: инновационное оценочное средство компетентности бакалавров Научно-педагогическое обозрение. Pedagogical Review. - 2013. $1(1)-$ C. 28-32.

8. Шеманаева М.А. Формирование универсальных компетенций бакалавра средствами иностранного языка // Высшее образование в России. Том 27, № 8-9, 2018. - C. 89 - 95. - https://doi.org/10.31992/0869-3617-2018-27-8-9-89-95

9. Prosekov A.Yu., Morozova I.S., Kretsan Z.V. Case study of the formation of the operational component of the psychological readiness of university graduates to overcome difficult life situations in their future professional activities // European Journal of Contemporary Education. 2021. Volume 10. № 1. pp. 103-112.

10. Yarosh 0.B., Zinoviev I.F. Educational standards and modern requirements: contradictions or opportunities // Education and Self-Development. 2021. Volume.16. № 1. pp. 116-128.

11. Yudina Y.G., Vasiliev V.G. Developing content and tools for assessing effectiveness of undergraduate programme in psychology and education // Психологическая наука и образование. 2019. Т. 24. № 1. С. 69-79.

(c) Назарова Наталья Александровна (geybel@rambler.ru), Назаров Сергей Владимирович (svnazaroff@rambler.ru). Журнал «Современная наука: актуальные проблемы теории и практики» 